\title{
Factors Affecting Mechanical Properties of the Skin of Sweet Cherry Fruit
}

\author{
Martin Brüggenwirth and Moritz Knoche ${ }^{1}$ \\ Institute for Horticultural Production Systems, Leibniz-University Hannover, Herrenhäuser Straße 2, \\ 30419 Hannover, Germany
}

\begin{abstract}
Additional IndeX words. Prunus avium, biaxial strain, cracking, fracture, tensile test, turgor
Aвstract. The skins of all fruit types are subject to sustained biaxial strain during the entire period of their growth. In sweet cherry (Prunus avium L.), failure of the skin greatly affects fruit quality. Mechanical properties were determined using a biaxial bulging test. The factors considered were the following: ripening, fruit water relations (including turgor, transpiration, and water uptake), and temperature. Excised discs of fruit skin were mounted in a custom elastometer and pressurized from their anatomically inner surfaces. This caused the skin disc to bulge outwards, stretching it biaxially, and increasing its surface area. Pressure $(p)$ and biaxial strain $(\varepsilon)$ due to bulging were quantified and the modulus of elasticity [ $E$ (synonyms elastic modulus, Young's modulus)] was calculated. In a typical

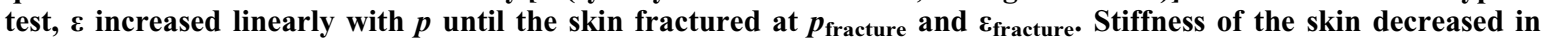
ripening late stage III fruit as indicated by a decrease in $E$. The value of $p_{\text {fracture }}$ also decreased, whereas that of $\varepsilon_{\text {fracture }}$ remained about constant. Destroying cell turgor decreased $E$ and $p_{\text {fracture }}$ relative to the turgescent control. The $E$ value also decreased with increasing transpiration, while $p_{\text {fracture }}$ and (especially) $\varepsilon_{\text {fracture }}$ increased. Water uptake had little effect on $E$, whereas $\varepsilon_{\text {fracture and }} p_{\text {fracture }}$ decreased slightly. Increasing temperature decreased $E$ and $p_{\text {fracture }}$, but had no effect on $\varepsilon_{\text {fracture }}$. Only the instantaneous elastic strain and the creep strain increased significantly at the highest temperatures. A decrease in $E$ indicates decreasing skin stiffness that is probably the result of enzymatic softening of the cell walls of the skin in the ripening fruit, of relaxation of the cell walls on eliminating or decreasing turgor by transpiration and, possibly, of a decreasing viscosity of the pectin middle lamellae at higher temperatures. The effects are consistent with the conclusion that the epidermal and hypodermal cell layers represent the structural "backbone" of the sweet cherry fruit skin.
\end{abstract}

Rain cracking is a limitation in sweet cherry production almost wherever this high-value crop is grown (Christensen, 1996). Fruit cracking in many species, including grape (Vitis vinifera L.) and sweet cherry, is thought to be related to water uptake by the fruit. Thus, any net water uptake necessarily increases fruit volume and subjects the skin to additional strain (Considine and Brown, 1981). If the limit of extensibility of the fruit skin is exceeded, the fruit cracks. On the basis of this concept, the following two categories of factors will affect cracking susceptibility: 1) the fruit's water uptake/loss characteristicsthese determine the rate and total amount of water accumulated by the fruit, and 2) the fruit's mechanical characteristics, particularly those of the principle load-bearing layer of the fruit-its skin (Brüggenwirth et al., 2014). Water uptake by sweet cherries has been investigated in some detail, including that through the fruit surface (Beyer et al., 2002, 2005; Beyer and Knoche, 2002; Weichert and Knoche, 2006) and that through the pedicel vasculature (Hovland and Sekse, 2004; Measham et al., 2010). In contrast, there have been only a few studies that have addressed the mechanical properties of the sweet cherry skin (Bargel et al., 2004; Brüggenwirth et al., 2014; Knoche and Peschel, 2006).

Investigating the mechanical properties of the fruit skin is challenging. First, the sweet cherry is about spherical and

Received for publication 17 Sept. 2015. Accepted for publication 27 Oct. 2015. This research was funded in part by a grant from the Deutsche Forschungsgemeinschaft. We thank Dieter Reese and Christoph Knake for constructing, engineering, and programming the elastometer, Friederike Schroeder and Simon Sitzenstock for technical support, Bishnu P. Khanal and Sandy Lang for helpful discussion and useful comments on an earlier version of this manuscript.

${ }^{1}$ Corresponding author. E-mail: moritz.knoche@obst.uni-hannover.de. hence, any strain of its skin during growth and water uptake is biaxial. Thus, a biaxial laboratory test is essential, if the in vivo strain in the skin is to be mimicked with any degree of accuracy. Second, uniaxial tests of skin strips result in marked narrowing of the sample as tension is applied. This is indexed by a high Poisson ratio and a gross overestimation of fracture strain and extensibility, and a gross underestimation of the $E$ (Brüggenwirth et al., 2014). Third, the sweet cherry skin is already markedly strained in vivo and these elastic and viscoelastic strains are reversible (Grimm et al., 2012). Thus, on excision the skin relaxes almost instantaneously and special care has to be taken to prevent this relaxation (Brüggenwirth et al., 2014).

The first biaxial tensile test for sweet cherry fruit skin was described by Bargel et al. (2004). Excised fruit skin segments were pressurized from the inner side and the extent of bulging for each pressure increment was quantified. Brüggenwirth et al. (2014) modified the test to prevent relaxation of the fruit skin after excision, thereby maintaining the in vivo strain in the fruit surface. Furthermore, the skin segments were pressurized using silicone oil rather than water thereby eliminating any uncontrolled water uptake and bursting of cells on the inner side (Simon, 1977). This test protocol offers a standardized test for identifying mechanical properties of sweet cherry fruit skins. Among the factors known to affect mechanical properties of fruit is the degree of ripening, especially during the later stages of development (Brummell, 2006; Christensen, 1996). Also, the fruit's turgescence is expected to be affected by the balance between transpiration and water uptake (Considine and Brown, 1981). Furthermore, many fleshy fruits, including sweet cherries, are soft to the touch when warm, but firmer at low temperatures (M. Brüggenwirth and M. Knoche, unpublished 
data). Also, increasing temperature markedly increased cracking (for review, see Christensen, 1996). As with all materials, one would expect the mechanical properties of a fruit skin to be affected by temperature.

The objectives of this study were to quantify the effects of 1) ripeness stage; 2 ) turgor, transpiration, and water uptake; and 3) temperature on the mechanical properties of sweet cherry fruit skin using a biaxial tensile test.

\section{Materials and Methods}

Plant material. Fruit of sweet cherry cultivars Adriana, Kordia, Sam, and Sweetheart were harvested at commercial maturity from field-grown or glasshouse-grown trees at the Horticultural Research Station of the Leibniz University in Ruthe, Germany (lat. $52^{\circ} 14^{\prime} \mathrm{N}$, long. $9^{\circ} 49^{\prime} \mathrm{E}$ ) in the 2012, 2013, and 2015 growing seasons. Trees were grafted on 'Gisela 5' rootstocks (Prunus cerasus L. $\times$ Prunus canescens Bois). Fruit were selected for freedom from visual defects and for uniformity of development based on size and color. In a preliminary experiment, the effect of storing sweet cherry at $2{ }^{\circ} \mathrm{C}$ and at water vapor concentrations close to saturation for up to $30 \mathrm{~d}$ on mechanical properties of the fruit skin was investigated. During the first $4 \mathrm{~d}$ of storage, stiffness of the skin increased as indexed by a $81 \%$ increase in the $E$. The pressure at fracture slightly increased $(+10 \%)$ and the strain at fracture decreased $[-26 \%$ (M. Brüggenwirth, unpublished data)]. There was no further change in mechanical properties between 4 and $30 \mathrm{~d}$ of storage. To avoid potential artifacts resulting from storage, all fruit were harvested in the mornings, covered by a damp paper towel, brought to the laboratory, and used in experiments within $2 \mathrm{~h}$.

General EXPerimental procedure. Biaxial tensile tests were performed using the elastometer described in detail by Brüggenwirth et al. (2014). Briefly, a brass washer (12 mm i.d.) was mounted on one of the two shoulders of a sweet cherry fruit using cyanoacrylate adhesive (Loctite 406; Henkel/Loctite Deutschland, Munich, Germany). Next, an exocarp segment [ES (synonym fruit skin segment)] comprising the exocarp and some adhering mesocarp [thickness (mean $\pm \mathrm{SE}$ ) $2.5 \pm 0.0 \mathrm{~mm}$ ] was excised by cutting horizontally beneath the washer using a razor blade. This procedure preserved the in vivo strain of the skin after excision (Brüggenwirth et al., 2014; Grimm et al., 2012; Knoche and Peschel, 2006). The brass washer with the ES was mounted in the elastometer, whose chamber was then filled with silicone oil (AK10; Wacker Chemie, Munich, Germany) and any visible air bubbles were carefully removed.

The chamber was pressurized by driving a motorized piston into the oil. This displaced the oil, reduced the chamber volume, and caused the ES to bulge outward. Pressure in the chamber was recorded using a pressure transducer (Typ 40PC100G; Honeywell International, Morristown, NJ) and the deflection of the bulging ES was recorded by the displacement transducer (KAP-S/5N; AST Angewandte System Technik, Wolnzach, Germany) of a universal material testing machine (BXCFR2.5TN; Zwick Roell, Ulm, Germany). Unless specified otherwise, pressure was increased continually until the ES fractured. The pressure at the moment of failure is referred to as the fracture pressure $\left[p_{\text {fracture }}\right.$ (kilopascals) $]$ and the area (i.e., biaxial) strain at failure as the fracture strain $\left[\varepsilon_{\text {fracture }}\right.$ (square millimeters per square millimeter)]. The strain $(\varepsilon)$ was calculated as the fractional increase in surface area; i.e., the increase in area $[\Delta A$ (square millimeters)] due to the bulging of the ES, relative to the initial area $\left[A_{0}\right.$ (square millimeters) $]$ before bulging:

$$
\varepsilon=\frac{\Delta A}{A_{0}}
$$

Surface areas of the ES were calculated from (changing) deflection height and the (fixed) diameter of the washer, and assumed a spherical shape (Brüggenwirth et al., 2014). Stiffness of the bulging ES was described by the $E$ using the equation described by Brüggenwirth et al. (2014), where $r$ (millimeters) is the radius of the washer orifice, $p$ (megapascals) the pressure, $h$ (millimeters) the height of the bulging ES, and $t$ the thickness of the load-bearing layer $(t=0.1 \mathrm{~mm})$ :

$$
E=\frac{p \times r^{2} \times\left(r^{2}+h^{2}\right)}{h^{3} \times t \times 2}
$$

Unless otherwise stated, experiments were conducted at $22{ }^{\circ} \mathrm{C}$.

EXPERIMENTS. Relationships between ripening during late stage III development and the mechanical properties of the fruit skin were investigated in 'Sweetheart' fruit. Fruit was sampled at $90,98,103$, and $110 \mathrm{~d}$ after full bloom for maximum difference in ripeness, the mass determined and fruit color quantified on the Commission Internationale de l'É-clariage (CIE) $1976\left(\mathrm{~L}^{*}, \mathrm{a}^{*}, \mathrm{~b}^{*}\right)$ scale as defined by the CIE (McGuire, 1992) using a chromameter (CR-200; Minolta, Osaka, Japan). To describe the change in color of the developing fruit, the hue angle was calculated as described by McGuire (1992). Three readings were taken per fruit that were averaged. Color is a good indicator of ripening in stage III sweet cherry (Hansen, 2011) and closely related to sugar content, whereas mass changes are usually quite small and fruit size is rather variable. For a representative batch (range in hue angle from $2.8^{\circ}$ to $30.0^{\circ}$ ) of 'Sweetheart' fruit, the regression equation describing the relationship between osmolarity and hue angle was: osmolarity (millimoles per kilogram) $=[0.86 \times$ hue angle $\left.(\text { degrees })^{2}\right]-[53.9 \times$ hue angle (degrees) $]+1742.7 ; r^{2}=$ $0.86^{* * *}$. There was no significant relationship between fruit mass and hue angle or mass and osmolarity (M. Brüggenwirth, unpublished data). Hence, the mechanical properties reported are expressed as a function of hue angle.

The effect of turgor on the mechanical properties of 'Adriana' ES was investigated by destroying membrane integrity of excised ES by a single freeze/thaw cycle $\left(-18^{\circ} \mathrm{C}\right.$ for $30 \mathrm{~min}$, followed by thawing for $30 \mathrm{~min}$ at $22^{\circ} \mathrm{C}$ ) or by solubilizing plasma membranes by incubating ES in a surfactant solution (1\% Triton X-100 for 12 h; Union Carbide, Antwerp, Belgium). Untreated ES served as controls. For technical reasons, the washer was mounted on the fruit before the freeze-thaw cycle and before the surfactant treatment and hence, the original strain of the turgescent fruit was preserved. There was no relaxation of the fruit skin during the treatment.

Potential relationships between the amount of water transpired and the mechanical properties of the skin were investigated in intact fruit of 'Sweetheart' sweet cherry. Fruit, with pedicel detached, were incubated in a sealed chamber for $0,24,48$, and $96 \mathrm{~h}$ above dry silica gel [0\% relative humidity (Geyer and Schönherr, 1988)]. To avoid confounding mass loss with storage duration, control fruit were stored in a sealed chamber above water (100\% relative humidity) for the same time periods. Weight loss due to transpiration was determined 
gravimetrically $(\mathrm{n}=20)$. Thereafter, ES were prepared, mounted in the elastometer and tested as described above.

The effect of the reverse process of osmotic water uptake on the mechanical properties of fruit skin was studied in a two-step experiment in 'Sweetheart'. First, the time course of water uptake and cracking was established. Water uptake was determined gravimetrically by incubating fruit in deionized water and subsequent weighing at $0,0.75$, and $1.5 \mathrm{~h}(\mathrm{n}=15)$. Cracking was monitored using a modified cracking assay as described by Verner and Blodgett (1931) and Christensen (1996). Fruit were inspected at $0,2,4,6,10$, and $24 \mathrm{~h}$ for macroscopically visible cracks. Because uptake and cracking were quantified on the same batch of fruit, the time to $50 \%$ and $100 \%$ cracking and the amount of water uptake at $50 \%$ and $100 \%$ cracking could be calculated. In the second part of the experiment, mechanical properties of the skin of fruit incubated in deionized water until $50 \%$ and $100 \%$ cracking was determined using the elastometer and the procedure described above. Fruit from the 50\% sampling was first partitioned into two populations-cracked and noncracked. Nonincubated (intact) fruit served as controls. The ES of cracked fruit was taken from the remaining intact shoulder of the fruit so that there was no confounding with position on the fruit. This procedure allowed comparison of mechanical properties of the skin of fruit that had cracked with those of fruit that under the same conditions had not cracked.

The effect of temperature on the mechanical properties of fruit skin of 'Sam' was investigated by carrying out a creep test at 5 , 15,25 , and $35^{\circ} \mathrm{C}$. In this assay, the ES were pressurized during the loading phase (I) by increasing pressure to $20 \mathrm{kPa}$ at a constant rate. During the subsequent hold, phase (II) pressure was held constant at $20 \mathrm{kPa}$ for $5 \mathrm{~min}$. Thereafter, pressure was increased until the skin segment fractured (III). This protocol allowed quantification of the following: elastic strain (I), creep strain (II), and fracture strain (III). The elastic component corresponded to deformation of the ES during the loading phase (I), the creep strain (the sum of viscoelastic strain and plastic strain) to that during the hold phase (II), and the fracture strain to that at fracture during phase (III) (Brüggenwirth et al., 2014). It should be noted that the sweet cherry skin on the fruit surface is already significantly strained (elastic, viscoelastic, and plastic) due to the deformation that occurred as a result of fruit growth (Grimm et al., 2012; Knoche et al., 2004). For estimates of a "total" strain that includes the fruit growth, these strains would have to be added to those determined in our biaxial tensile tests.

DAta Analysis. Data analyses were limited to those fruit skin segments that fractured in the center of the orifice of the elastometer. ES that fractured at the edge were excluded from analysis because this could have resulted from a mounting artifact (Brüggenwirth et al., 2014). Data are presented as values of individual fruit (Figs. 1, 2B-D, 3B-D, and 5A and B) or as means \pm SE (Figs. 2A, 3A, 4, and $5 \mathrm{C}$ and D). Mean comparisons were conducted using Tukey's Studentized range test $(P<0.05$; packet multcomp $1.2-12$, procedure glht, $\mathrm{R}$ 2.13.1; R Foundation for Statistical Computing, Vienna, Austria). Significance of coefficients of correlation $(r)$ and determination $\left(r^{2}\right)$ at the $0.05,0.01$, and $0.001 P$ levels is indicated by $*, * *$, and $* * *$, respectively.

\section{Results}

Pressure and biaxial strain increased linearly with time until the skin segment fractured (Fig. 1A). The $E$ calculated from

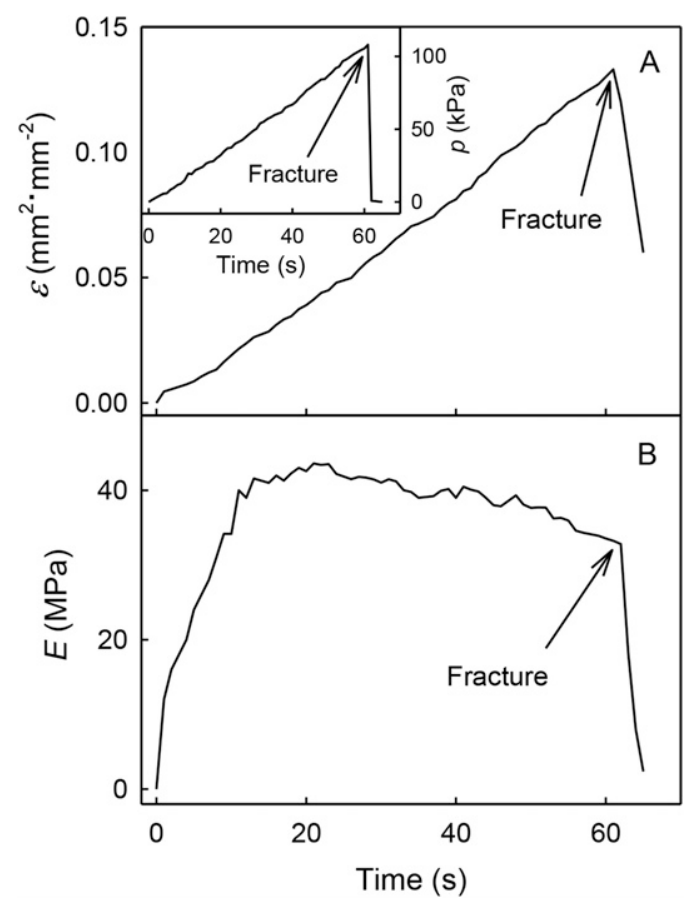

Fig. 1. Time course of increase in (inset $\mathbf{A}$ ) pressure $(p),(\mathbf{A})$ strain $(\varepsilon)$, and $(\mathbf{B})$ modulus of elasticity $(E)$ of a bulging skin segment of a mature sweet cherry fruit mounted in the elastometer (a typical result).

paired data for pressure and strain, increased to a maximum $\approx 20 \mathrm{~s}$ after test initiation and then declined slightly before the segment fractured (Fig. 1B).

During ripening in late stage III fruit, fruit mass increased and at the same time hue angle decreased, implying that the fruit darkened (Fig. 2A). The progress of ripening was more consistently represented when expressed as a color change, than as a mass change. The decrease in hue angle associated with increasing ripening was accompanied by a decreased $E\left(r^{2}=\right.$ $0.68 * * *)$ and $p_{\text {fracture }}\left(r^{2}=0.80 * * *\right)$, but had no effect on $\varepsilon_{\text {fracture }}$ $\left(r^{2}=0.19\right)$ (Fig. 2B-D).

Compared with the turgescent control, destroying membrane integrity by a single freeze-thaw cycle or by incubating skin segments in a surfactant solution decreased $E$ and $p_{\text {fracture, }}$, but had no effect on $\varepsilon_{\text {fracture }}$ (Table 1 ).

The amount of water transpired increased linearly with time above dry silica, but there was no change in mass over the same time period at $100 \%$ relative humidity [Fig. 3A (inset)]. Mechanical properties were variable and depended on the mass of water transpired. The value of $E$ decreased with increasing transpiration, whereas that of $p_{\text {fracture }}$ and, especially, of $\varepsilon_{\text {fracture }}$ increased significantly with transpiration. Slopes of linear regressions and coefficients of determination for these relationships were: $E, \mathrm{a}=-8.5 \pm 1.2 \mathrm{MPa} \cdot \mathrm{g}^{-1}, r^{2}=0.51^{* * *} ; p_{\text {fracture }}, \mathrm{a}=$ $6.0 \pm 1.3 \mathrm{kPa} \cdot \mathrm{g}^{-1}, r^{2}=0.36^{* * *} ; \varepsilon_{\text {fracture }}, \mathrm{a}=0.05 \pm 0.003$ $\mathrm{mm}^{2} \cdot \mathrm{mm}^{-2} \cdot \mathrm{g}^{-1}, r^{2}=0.77^{* * *}$, respectively (Fig. 3A-C). Quantitatively similar data were obtained in 'Kordia' (M. Brüggenwirth, data not shown).

Cumulative water uptake increased linearly with time up to $1.5 \mathrm{~h}$ [Fig. 4 (inset)], whereas the percentage of cracked fruit increased sigmoidally with time and cumulative water uptake (Fig. 4). From these relationships, the time required to achieve $0 \%, 50 \%$, and $100 \%$ of cracked fruit was calculated. Fruit incubated for a period equal to the $50 \%$ cracking threshold were 

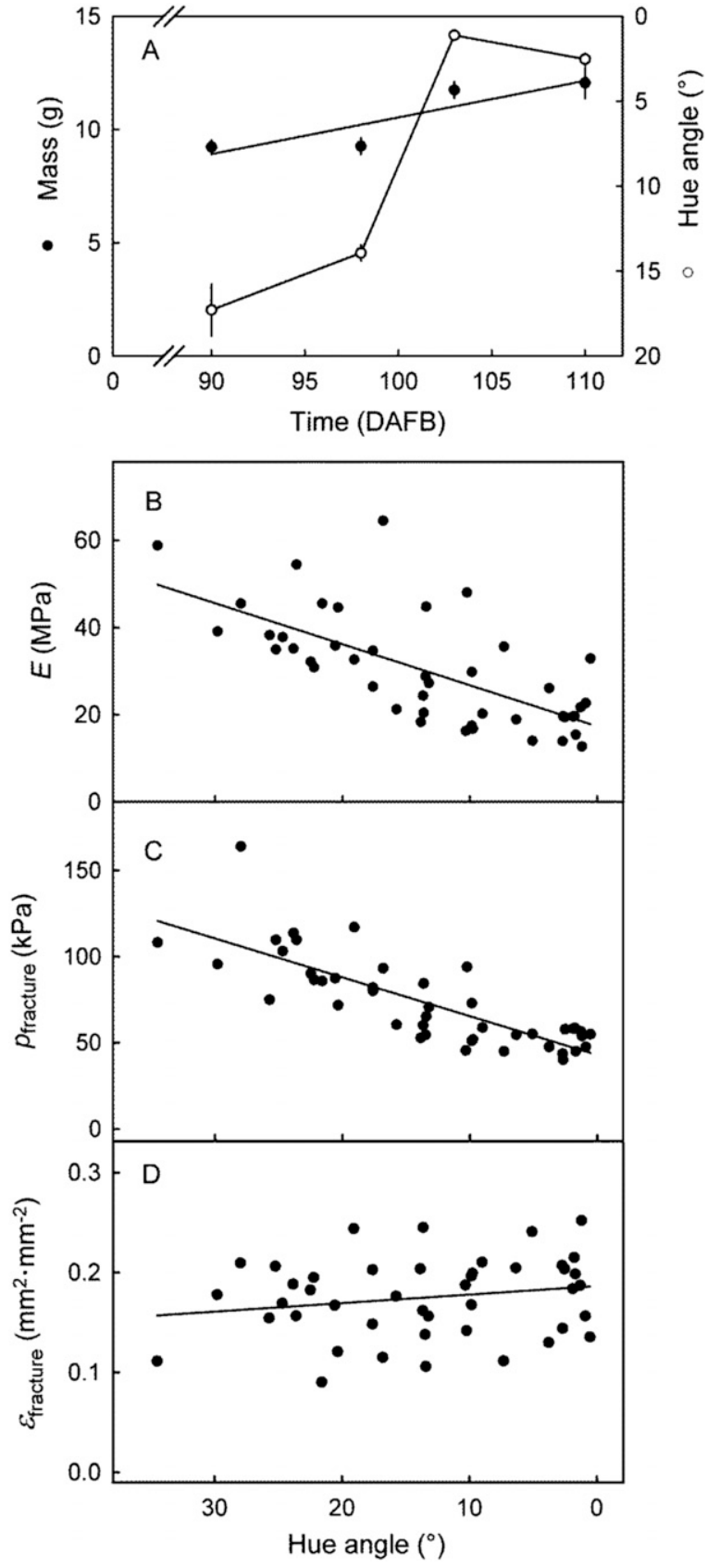

Fig. 2. Relationship between late stage III development of sweet cherry fruit and the mechanical properties of the skin. (A) Time course of change in fruit mass and color as indexed by the hue angle. (B-D) Relationships between the hue angle of the fruit skin and the mechanical properties of the skin as indexed by $(\mathbf{B})$ its modulus of elasticity $(E),(\mathbf{C})$ pressure at fracture ( $\left.p_{\text {fracture }}\right)$, and (D) strain at fracture $\left(\varepsilon_{\text {fracture }}\right)$. High hue angles imply less mature, pale fruit, low hue angles imply more mature, darker fruit. $X$-axis scale in (A) in days after full bloom (DAFB). Values in (A) represent means $\pm \mathrm{SE}(\mathrm{n}=5-30)$, those in $\mathbf{B}-\mathbf{D}$ individual fruit.

subdivided in two, roughly equal, populations - cracked and noncracked. Biaxial tensile tests revealed no effect of water uptake and/or cracking status on $E$, whereas $p_{\text {fracture }}$ and or $\varepsilon_{\text {fracture }}$ slightly decreased in cracked fruit (Table 2).

Increasing pressure during the loading phase (I) increased the instantaneous elastic strain at all temperatures (Fig. 5A). In the subsequent holding phase (II) at constant pressure, the skin stretched due to creep strain, comprising both viscoelastic and plastic strain components. In the final phase (III), an increase in
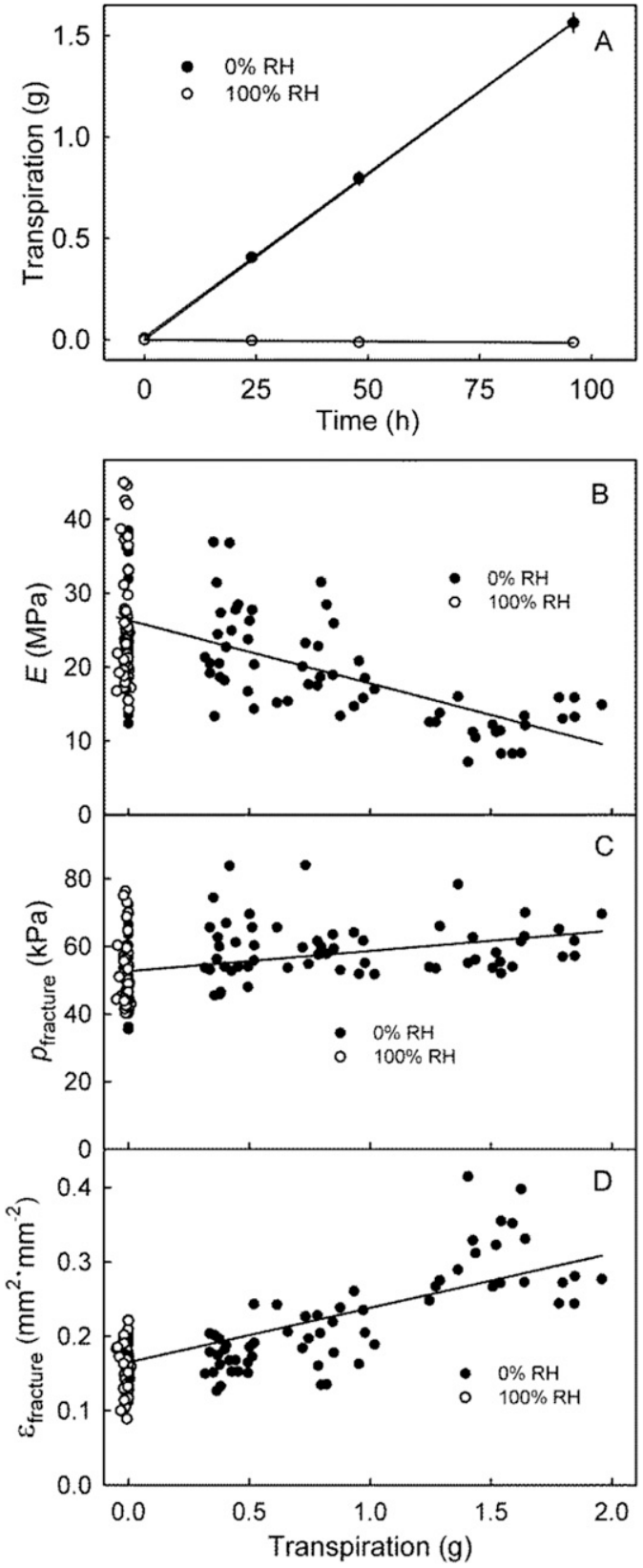

Fig. 3. Effect of transpiration of sweet cherry fruit on the mechanical properties of the excised skin. (A) Time course of transpiration. Mechanical properties were indexed by the $(\mathbf{B})$ modulus of elasticity $(E),(\mathbf{C})$ pressure at fracture $\left(p_{\text {fracture }}\right)$, and $(\mathbf{D})$ strain at fracture $\left(\varepsilon_{\text {fracture }}\right)$. Values in $(\mathbf{A})$ represent means \pm SE $(n=20)$, those in $\mathbf{B}-\mathbf{D}$ individual fruit. Fruit held at $100 \%$ relative humidity $(\mathrm{RH})$ for the same period of time served as control.

pressure resulted in failure of the skin at all temperatures. Increasing temperature decreased the values of $E$ and $p_{\text {fracture }}$ (Fig. 5C), but had no effect on that of $\varepsilon_{\text {fracture }}\left\{\varepsilon_{\text {fracture }}\right.$ (square millimeters per square millimeter $)=[0.159( \pm 0.01) \times$ temperature $\left.\left.\left({ }^{\circ} \mathrm{C}\right)\right]+0.0004( \pm 0.0005), r^{2}=0.52 *\right\}$. Only the instantaneous elastic strain and creep strain increased significantly at the highest temperature (Fig. 5D).

\section{Discussion}

The mechanical properties of the skin of a sweet cherry fruit are primarily determined by the epidermal and the hypodermal 


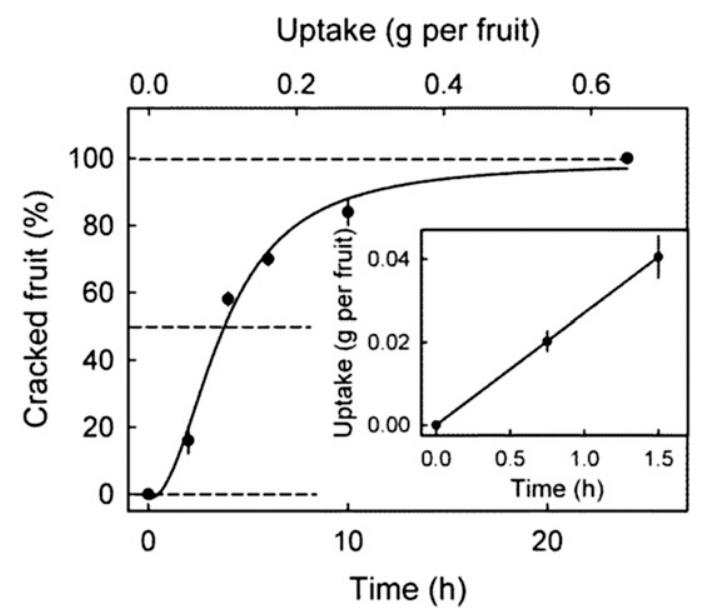

Fig. 4. Time courses of cracking (main graph) and of water uptake (inset) in sweet cherry fruit incubated in deionized water. Dashed lines indicate times and cracking levels when fruit were sampled for determining the mechanical properties of excised skin samples. For details of mechanical tests, see Table 2.

layers (Brüggenwirth et al., 2014; Grimm et al., 2012). Thus, any effects of the factors investigated here must be accounted for within these two tissues. Mechanically relevant properties of soft tissues include the amount of applied stress, the properties of cell walls, and of the middle lamellae. Also involved are cell turgor, the permeability of the plasma membrane, and the sizes and shapes of the cells (Niklas, 1992; Vincent, 1990a).

\section{Effect of ripening}

Fruit ripening is characterized by softening due to the activity of cell wall-degrading enzymes, particularly pectinases (Andrews and Li, 1995; Barrett and Gonzalez, 1994; Brummell, 2006). In 'Satoshniki' sweet cherry, the cleavage of neutral sugar side chains from pectins is causal in fruit softening (Kondo and Danjo, 2001). Also, when incubating fruit in water, soluble pectin increased in solution (Glenn and Poovaiah, 1989). The role of cellulase in cell wall degradation and softening of cherry is not clear. There was no evidence of cellulase activity during ripening in 'Royal Anne' and 'Bada' (Barrett and Gonzalez, 1994), whereas cellulase activity increased in 'Bing' (Andrews and Li, 1995). The changes in the skin's mechanical properties during ripening are consistent with enzymatic cell wall degradation. The progressive reduction in $E$ is indicative of decreased stiffness and increased softening. Furthermore, the reduction in $p_{\text {fracture }}$ is consistent with a continuing softening primarily caused by increased pectinase activity.

The $E$ values measured in the sweet cherry skin are of similar order of magnitude as those from other biaxial tests of skins of apple [Malus $\times$ domestica Borkh., $76.1 \pm 8.7 \mathrm{MPa}$ (M. Brüggenwirth, unpublished data)], tomato [Solanum lycopersicum L., $55.9 \pm$ 9.6 $\mathrm{MPa}$ (M. Brüggenwirth, unpublished data)], sour cherry (Prunus cerasus; range $3.5 \pm 0.2$ to $5.9 \pm 0.2 \mathrm{MPa}$ ), cape gooseberry (Physalis peruviana L., $20.5 \pm 0.8 \mathrm{MPa}$ ), european plum (Prunus $\times$ domestica L., $25.4 \pm 7.8$ to $35.9 \pm 3.2 \mathrm{MPa}$ ), and grapes $(20.8 \pm 1.7$ to $21.5 \pm 1.6 \mathrm{MPa})$ (Brüggenwirth et al., 2014 ) or from uniaxial tests of skins of tomato [43.5 \pm 4.8 and $27.1 \pm 1.9 \mathrm{MPa}$ for 'Inbred 10' and 'Sweet 100', respectively (Matas et al., 2004)], or apple [16.6 $\pm 1.2 \mathrm{MPa}$ (B.P. Khanal, unpublished data)].
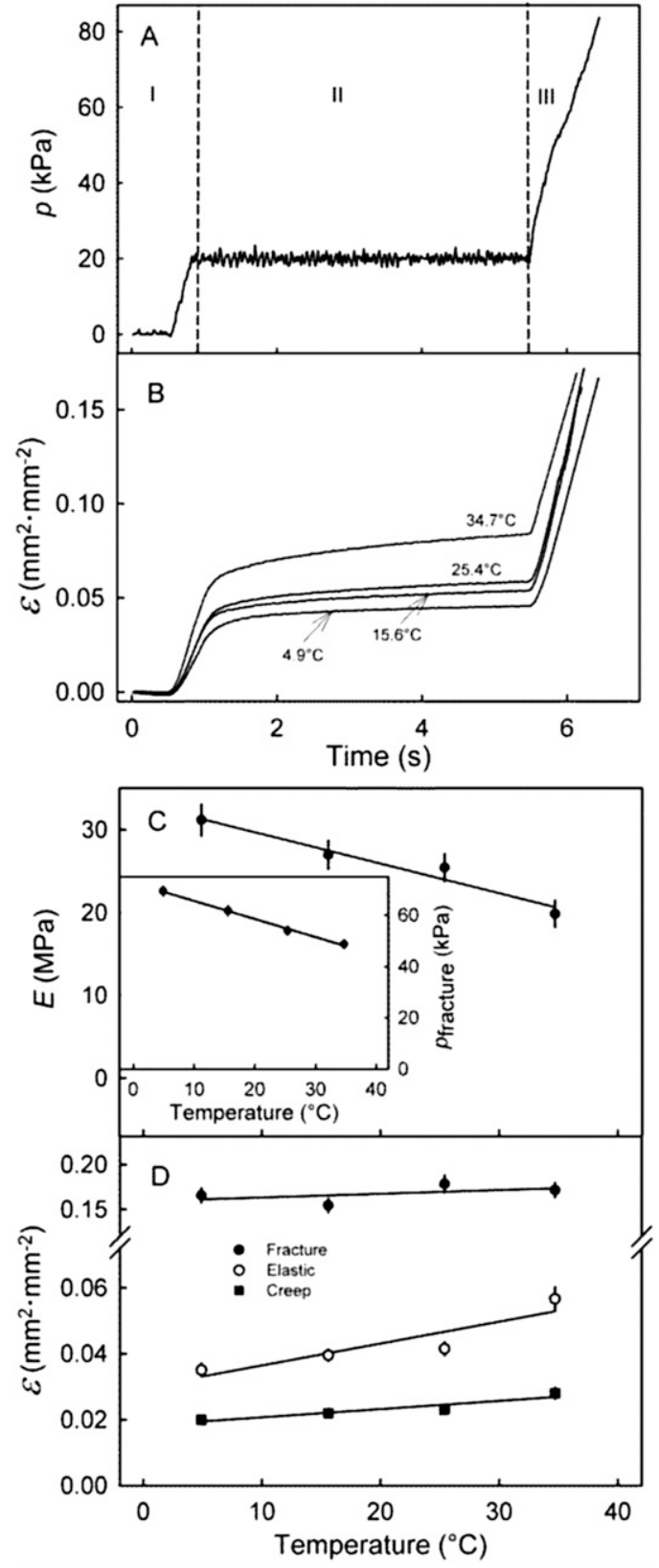

Fig. 5. Effect of temperature on the mechanical properties of the skin of sweet cherry fruit as determined in a biaxial creep test. (A) Representative time course of pressure $(p)$ applied to the skin. The pressure was increased during the initial loading phase (I), held constant during the holding phase (II), and increased until skin fracture (III). (B) Representative time courses of strains $(\varepsilon)$. (C and D) Effect of temperature on the $(\mathbf{C})$ modulus of elasticity $E$ ) and (inset $\mathbf{C}$ ) pressure at fracture $\left(p_{\text {fracture }}\right)$, and (D) the elastic and the creep strain $(\varepsilon)$. The elastic component corresponds to instantaneous deformation of the skin during phase (I). The creep strain (sum of viscoelastic strain plus plastic strain) refers to the deformation of the exocarp segment during phase (II). Values in $\mathbf{C}$ and $\mathbf{D}$ represent means $\pm \mathrm{SE}(\mathrm{n}=21)$.

\section{Effect of turgor, transpiration, and water uptake}

The effects of water loss and water uptake on the mechanical properties of the skin are accounted for primarily by changes in the physical properties of the cell walls caused by the manipulation of factors affecting turgor. If turgor is eliminated by destroying the membranes, water moves more freely and the cell walls relax. This releases reversible strain (Grimm et al., 2012) and results in decreased stiffness as indexed by a lowering 
of $E$ and $p_{\text {fracture. These data are consistent with those reported }}$ by Oey et al. (2007) in which relationships between tissue turgor and mechanical properties in apples were investigated. The only difference between the findings by Oey et al. (2007) in apple and our observations for sweet cherry skin is the apparent lack of an effect of eliminating turgor on $\varepsilon_{\text {fracture }}$. Oey et al. (2007) reported an increase in $\varepsilon_{\text {fracture }}$ in apple. This discrepancy is probably related to differences in experimental procedure. In our tensile tests, the skin was mounted in a washer that prevented relaxation associated with turgor elimination (Knoche and Peschel, 2006). If it were technically possible to mount a relaxed cherry fruit in the elastometer washer [which it is not (M. Brüggenwirth, unpublished data)], we would expect $\varepsilon_{\text {fracture }}$ to increase after eliminating turgor.

It is important to point out that the low turgor in sweet cherry fruit relative to the $\psi_{\mathrm{S}}$ (Knoche et al., 2014; Schumann et al., 2014) is not necessarily contradictory to a role of turgor in tensile properties of the tissue. The water in the symplast is not compressible and so, regardless of cell turgor, will oppose any sudden change in skin cell shape, such as a decrease in the diameter:thickness ratio that is inevitably associated with biaxial stretching. Mechanically, turgor is maintained by elastic strain in the cell wall (Niklas, 1992; Vincent, 1990a). De Belie et al. (2000) argued that the effect of turgor on the tensile properties of flesh samples of european pear (Pyrus communis L.) and asian pear [Pyrus pyrifolia (Burm. f.) Nakai] was related to their mode of failure. Turgor had no effect on the measured tissue failure properties, when failure occurred along cell walls between cells as opposed to across cell walls by cell wall fracture (De Belie et al., 2000). In addition, an abrupt decrease in the force at failure of apple flesh subjected to tensile tests was interpreted as evidence of cell rupture (Oey et al., 2007). If these conclusions for apple are also applicable to the skin of sweet cherries, then the effect of turgor in our study would be indicative of failure across cell walls. Unfortunately, definitive evidence is lacking. As far as we are aware, the mode of failure of the skin in sweet cherry fruit cracking has not yet been critically investigated.
Transpiration causes fruit shrinkage, and thus results in decreasing biaxial strain and stress in the skin and a relaxation of their cell walls (Grimm et al., 2012). This explanation accounts for the effect of transpiration on the mechanical properties of the fruit skin observed in our study. Fruit mass decreased by $\approx 1.56 \pm 0.05 \mathrm{~g}$ during transpiration. For a $10 \mathrm{~g}$ fruit of spherical shape, a $1.6 \mathrm{~g}$ mass loss translates to a $10.7 \%$ decrease in skin surface area. This estimate corresponds well with the measured increase in $\varepsilon_{\text {fracture }}$ of $14.6 \%$ (Fig. 3). This explanation also holds for the loss of stiffness as indexed by the decrease in $E$. The slight increase in $p_{\text {fracture }}$ with increasing transpirational water loss may be accounted for by the decreasing volume of the shrinking and relaxing cells and the corresponding increase in the amount of cell wall material per unit area of the fruit surface.

For the opposite process, water uptake, we expect similar changes to those for transpiration but in the opposite direction. However, water uptake had only small, essentially negligible, effects on the mechanical properties of the skin. The most likely explanation for this apparent contradiction is that the scale of the mass change caused by water uptake was much smaller $(0.65 \pm 0.12 \mathrm{~g})$ than that caused by transpiration $(-1.56 \pm 0.05 \mathrm{~g})$. Consequently, the increase in strain associated with water uptake was surprisingly small and unexpected, particularly in the light of $100 \%$ cracking at the longest exposure. Several factors must be considered:

1) The biaxial tensile test focuses on the fruit skin. Any effects of the flesh are largely eliminated by its substantial removal from the sample. Flesh effects in vivo (before excision) will include exposure to juice resulting from compartmentation loss (particularly around the pit) or heterogeneity arising from localized cell death. Both these effects have been demonstrated for grape berries that have similar mechanical architecture to sweet cherry (Considine and Brown, 1981; Lang and Düring, 1991; Tilbrook and Tyerman, 2008) and malic acid, a major constituent of sweet cherry fruit juice, markedly increases sweet cherry cracking (Winkler et al., 2015). Also, in

Table 1. Effect of turgor on mechanical properties of the sweet cherry fruit skin as indexed by the modulus of elasticity $(E)$, pressure at fracture $\left(p_{\text {fracture }}\right)$, and strain at fracture $\left(\varepsilon_{\text {fracture }}\right)$. Turgor was destroyed by subjecting excised fruit skin to a freeze-thaw cycle or by incubating it in $1 \%$ Triton X-100 surfactant (Union Carbide, Antwerp, Belgium) for $12 \mathrm{~h}$. Before eliminating turgor, fruit skin segments were mounted in a washer to prevent relaxation on excision.

\begin{tabular}{lcccc}
\hline & & $E$ & $p_{\text {fracture }}$ & $\varepsilon_{\text {fracture }}$ \\
\cline { 3 - 5 } Treatment & $\mathrm{n}$ & $14.3 \pm 0.9 \mathrm{a}^{\mathrm{z}}$ & $29 \pm 1.7 \mathrm{a}$ & $0.17 \pm 0.01 \mathrm{a}$ \\
\hline Control & 15 & $7.9 \pm 0.9 \mathrm{~b}$ & $14 \pm 1.0 \mathrm{~b}$ & $0.17 \pm 0.01 \mathrm{a}$ \\
Freeze/thaw & 15 & $8.6 \pm 0.6 \mathrm{~b}$ & $19 \pm 1.0 \mathrm{~b}$ & $0.19 \pm 0.01 \mathrm{a}$ \\
Surfactant & 18 & [mean $\pm \mathrm{SE}(\mathrm{MPa})$ & $\mathrm{SE}$ & \\
\hline
\end{tabular}

${ }^{\mathrm{z}}$ Mean separation within columns by Tukey's Studentized range test at $P<0.05$.

Table 2. Effect of incubation of sweet cherry fruit in deionized water on cracking and on the mechanical characteristics of the fruit skin. The characteristics quantified in the biaxial tensile test were the modulus of elasticity $(E)$, the pressure at fracture $\left(p_{\text {fracture }}\right)$, and the strain at fracture $\left(\varepsilon_{\text {fracture }}\right)(\mathrm{n}=10)$.

\begin{tabular}{|c|c|c|c|c|c|}
\hline Incubation time $(\mathrm{h})$ & Fruit cracking (\%) & Tested fruit & $\frac{E}{[\text { mean } \pm \mathrm{SE}(\mathrm{MPa})]}$ & $\frac{p_{\text {fracture }}}{[\text { mean } \pm \mathrm{SE}(\mathrm{kPa})]}$ & $\frac{\varepsilon_{\text {fracture }}}{\left[\text { mean } \pm \mathrm{SE}\left(\mathrm{mm}^{2} \cdot \mathrm{mm}^{-2}\right)\right]}$ \\
\hline 0 & 0 & Intact & $19.8 \pm 1.8 \mathrm{a}^{\mathrm{z}}$ & $58.6 \pm 3.8 \mathrm{a}$ & $0.22 \pm 0.01 \mathrm{a}$ \\
\hline 3 & 50 & Intact & $32.2 \pm 7.9 \mathrm{a}$ & $50.9 \pm 2.1 \mathrm{ab}$ & $0.16 \pm 0.02 \mathrm{ab}$ \\
\hline 24 & 100 & Cracked & $32.9 \pm 5.2 \mathrm{a}$ & $41.2 \pm 2.2 b$ & $0.12 \pm 0.01 \mathrm{~b}$ \\
\hline
\end{tabular}

${ }^{\mathrm{z}}$ Mean separation within columns by Tukey's Studentized range test at $P<0.05$. 
our earlier study, we observed a slight decrease in $\varepsilon_{\text {fracture }}$ when thickness of the ES increased (Brüggenwirth et al., 2014). Structural heterogeneity could also arise from the presence of vascular bundles. In cherry, these lie just beneath the epidermal and hypodermal cell layers, $\approx 2.1 \pm 0.1 \mathrm{~mm}$ below the fruit surface (M. Brüggenwirth unpublished data). Because the thickness of the experimental skin segments averaged $2.4 \pm$ $0.0 \mathrm{~mm}$ (Brüggenwirth et al., 2014), vascular bundles would likely have been present in all segments. If these should give rise to structural heterogeneity in the excised skin or in the intact fruit, the distribution of stress and strain could be nonuniform and this could cause failure (Brown and Considine, 1982). The strength of the weakest link would then determine the strength of the entire skin. At this stage, we have found no evidence that this is a significant factor.

2) The fruit skins selected for biaxial strain testing were free of visible blemishes. This was necessary because fruit having visible skin cracks cannot be mounted in the elastometer. It may be argued that this selection may have eliminated susceptible, predamaged fruit. However, a bias is unlikely to have occurred because the fruit used in the cracking assay were from the same batch and subjected to the same selection procedure.

3) Biaxial testing is best performed on skin segments from regions of the fruit that have uniform curvature of maximum radius of curvature. Skin from the stem cavity region is concave and, therefore, impossible to investigate. That from the stylar scar region is convex but has asymmetric curvature. The shoulder, cheek, and suture regions are best having more uniform curvatures. It may be argued that cracking occurs most frequently in the stylar scar and stem cavity regions (Knoche and Peschel, 2006; Yamaguchi et al., 2002) where microscopic cracks are also more frequent (Peschel and Knoche, 2005). Because of likely microcracking, the shoulder region would have been less satisfactory for quantifying cracking-relevant properties of the skin on this account too. Nevertheless, preliminary tests showed that some of these factors are of little account anyway because when results were compared for skin segments from cheek, shoulder, suture, and stylar scar regions, only slight differences in $E$ (range $16.7 \pm 0.9$ to $21.7 \pm 1.2 \mathrm{MPa}$ ), $p_{\text {fracture }}\left(\right.$ range $62 \pm 3$ to $73 \pm 2 \mathrm{kPa}$ ), and $\varepsilon_{\text {fracture }}$ (range $0.18 \pm$ 0.01 to $0.27 \pm 0.01 \mathrm{~mm}^{2} \cdot \mathrm{mm}^{-2}$ ) were obtained (M. Brüggenwirth, unpublished data).

\section{Effect of temperature}

Our results establish that skin stiffness decreases with rising temperature. This property fits with the norm for most materials, not just with biological ones (Niklas, 1992). It is also consistent with our earlier observations for rising temperatures of a more rapid and greater relaxation of ES (Grimm et al., 2012) and increased creep strain (Niklas, 1992). It is also in line with earlier observations that cracking is more severe under warmer conditions (Christensen, 1996). Likewise in grape, Lang and Düring (1990) reported a decrease in stiffness and strength as temperature increased. Vincent (1990b) hypothesized that the effect of temperature on mechanics of plant tissues may be related to the viscoelastic properties of the middle lamellae. At higher temperatures, stiffness will decrease because the viscosity of pectins is known to decrease (Kar and Arslan, 1999), making the "glue" between adjacent cells less stiff. However, direct evidence for many of these mechanisms is still lacking. Some of these features could even account for the effects of temperature on fruit texture-they feel firmer when cool, softer when warm.

Practical implications. The changes in mechanical properties observed here in response to ripening, water uptake, and increasing temperature, are broadly in line with reports of increased cracking susceptibility in more mature fruit and at higher temperatures (for review, see Christensen, 1996). Also, based on the critical turgor pressure concept, increased turgor should result in increased cracking susceptibility (Measham et al., 2009; Sekse et al., 2005) but direct experimental evidence for this view, seems to be lacking. Actually, the turgor recorded in cells of the outer mesocarp is very low, relative to their $\psi_{\mathrm{S}}$, hence, increased turgor as the cause of fruit cracking becomes very unlikely (Knoche et al., 2014; Schumann et al., 2014).

It is interesting that for excised skin, the applied pressure at fracture in the elastometer is of similar magnitude to measurements of both fruit turgor and of cell turgor in still-attached skin. This contrasts with measurements of the strain at fracture in the elastometer, which are markedly greater than the strains at fracture, measured for still-attached skins under water (Brüggenwirth et al., 2014; Schumann et al., 2014). The amount of water taken up at $50 \%$ cracking $\left(\mathrm{WU}_{50}\right)$ typically ranges from 24 to $234 \mathrm{mg} /$ fruit (Weichert et al., 2004; Winkler et al., 2015). Assuming a spherical, $10 \mathrm{~g}$ fruit, having a density of $1 \mathrm{~kg} \cdot \mathrm{dm}^{-3}$ and a surface area of $22.4 \mathrm{~cm}^{2}$, this would be

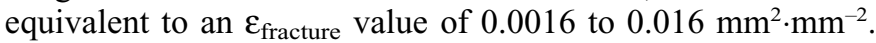
Making the same calculation for cracking thresholds of $0.44 \%$ (Christensen, 1996), up to a 13\% water uptake (Kertesz and Nebel, 1935) yields an $\varepsilon_{\text {fracture value between } 0.0029 \text { and } 0.085}$ $\mathrm{mm}^{2} \cdot \mathrm{mm}^{-2}$. These $\varepsilon_{\text {fracture }}$ are markedly lower than those measured for excised skin in the elastometer. The reasons for this difference are unknown but may be related to one or more of the following: first, the surface area of a complete fruit is very much greater than that of a skin segment in the elastometer. The ratio of surface area of fruit to that of the ES $(\approx 20: 1)$ will increase the probability (20-fold) that a skin defect might initiate a crack. Indeed, in our earlier study, we observed decreased pressures at fracture and decreased strains at fracture as segment areas in the elastometer increased. This is consistent with a "defect" hypothesis (Brüggenwirth et al., 2014). Second, the rates of strain in the elastometer $(\approx 0.20$ $\left.\mathrm{mm}^{2} \cdot \mathrm{mm}^{-2} \cdot \mathrm{min}^{-1}\right)$ greatly exceed those associated with water uptake in intact fruit $\left(\approx 0.03 \mathrm{~mm}^{2} \cdot \mathrm{mm}^{-2} \cdot \mathrm{min}^{-1}\right)$. The effect of strain rate on the mechanical characteristics of sweet cheery skin has not yet been studied. Nevertheless, for viscoelastic materials in general, one expects a low strain rate to yield a higher value for strain at fracture, and a lower pressure at fracture (vice versa for a high strain rate). This suggests that the strain rate difference is an unlikely explanation for what we observe. Third, the skin of a submerged fruit is wet, whereas the skin sample in the elastometer is dry. We know, surface wetness induces microcracks in the sweet cherry cuticle (Knoche and Peschel, 2006). However, wetness had no effect on the mechanical properties of the skin in a head-to-head comparison of dry skin $\left(\varepsilon_{\text {fracture }} 0.21 \pm 0.01 \mathrm{~mm}^{2} \cdot \mathrm{mm}^{-2}\right)$ vs. wet skin $\left(\varepsilon_{\text {fracture }}\right.$ $0.22 \pm 0.01 \mathrm{~mm}^{2} \cdot \mathrm{mm}^{-2}$; M. Brüggenwirth, unpublished data). Also, microcracks in the cuticle have no direct effects on the skin's mechanical properties (Brüggenwirth et al., 2014). Fourth, differential responses among cultivars can be excluded as a potential explanation since, in our cultivar comparisons, the range in $\varepsilon_{\text {fracture }}$ (range $0.17 \pm 0.01$ to $0.22 \pm 0.01 \mathrm{~mm}^{2} \cdot \mathrm{mm}^{-2}$; M. Brüggenwirth, unpublished data) was very much smaller 
than the difference between the $\varepsilon_{\text {fracture value determined using }}$ the elastometer and that calculated from the volume of water uptake at cracking. The former were an order of magnitude greater.

Our use of a range of cultivars in the different experiments deserves some comment. For each cultivar, and from each location, top-quality fruit is available for only a few days each season. Hence, for research involving time-consuming, sequential, experimentation, the use of a range of cultivars grown under a range of conditions (sites, seasons, etc.) is undesirable, but unavoidable. However, looking on the positive side, this can be considered to expand the generality of our conclusions compared with a hypothetical situation where it was possible to obtain more uniform samples (single cultivar, single source) over an extended period. It should also be recognized that our experiments were structured such that this diversity of cultivar and source does not introduce logical problems of interpretation. First, our comparisons were limited to head-to-head comparisons of treatments within each experiment and using appropriate controls. Second, there is no published evidence (nor is it very likely) that the mechanism of skin failure on a fruit's shoulder will differ much among cultivars. Third, the experiments focus on individual factors affecting the mechanical properties of the fruit skin and there is no published or intrinsic evidence for any interaction among these factors and cultivar. Clearly, quantitative responses will likely differ among cultivars and sources (and seasons etc.), but qualitatively they seem to remain much the same.

\section{Conclusions}

Our experiments indicate skin stiffness decreases with ripening, decreasing turgor (increased transpiration), elimination of turgor (freeze/thaw), and increasing temperature. These responses could well find their explanations in a series of changes including the following: enzymatic softening of the cell wall during ripening, relaxation of the cell wall on artificially decreasing or eliminating turgor, and a potential decrease in viscosity of the pectin middle lamellae at higher temperatures (as hypothesized by Vincent, 1990b). These conclusions are also consistent with earlier studies that have identified the epidermal and hypodermal cell layers (and "not" the cuticle) as the structural "backbone" of a sweet cheery skin (Brüggenwirth et al., 2014; Grimm et al., 2012).

It is interesting that the fruit pressure at fracture is of similar magnitude to normal fruit turgor (the average turgor of a population of healthy fruit on the tree), as previously reported (Knoche et al., 2014; Schumann et al., 2014). However, the strain at fracture (here and previously, Brüggenwirth et al., 2014) is significantly greater in biaxial tensile skin tests than in estimates based on the water uptake of submerged fruit. The mechanistic basis of this observation is unclear, with detailed studies being required to elucidate it. Such studies might usefully include a modification of the elastometer to allow variations to be made in strain rate for kinetic studies.

\section{Literature Cited}

Andrews, P.K. and S. Li. 1995. Cell wall hydrolytic enzyme activity during development of nonclimacteric sweet cherry (Prunus avium L.) fruit. J. Hort. Sci. 70:561-567.
Bargel, H., H.C. Spatz, T. Speck, and C. Neinhuis. 2004. Twodimensional tension test in plant biomechanics-Sweet cherry fruit skin as a model system. Plant Biol. 6:432-439.

Barrett, D.M. and C. Gonzalez. 1994. Activity of softening enzymes during cherry maturation. J. Food Sci. 59:574-577.

Beyer, M. and M. Knoche. 2002. Studies on water transport through the sweet cherry fruit surface: V. Conductance for water uptake. J. Amer. Soc. Hort. Sci. 127:325-332.

Beyer, M., S. Peschel, M. Knoche, and M. Knörgen. 2002. Studies on water transport through the sweet cherry fruit surface: IV. Regions of preferential uptake. HortScience 37:637-641.

Beyer, M., S. Lau, and M. Knoche. 2005. Studies on water transport through the sweet cherry fruit surface: IX. Comparing permeability in water uptake and transpiration. Planta 220:474-485.

Brown, K. and J. Considine. 1982. Physical aspects of fruit growth: Stress distribution around lenticels. Plant Physiol. 69:585-590.

Brummell, D.A. 2006. Cell wall disassembly in ripening fruit. Funct. Plant Biol. 33:103-119.

Brüggenwirth, M., H. Fricke, and M. Knoche. 2014. Biaxial tensile tests identify epidermis and hypodermis as the main structural elements of sweet cherry skin. Ann. Bot. Plants 6:plu019.

Christensen, J.V. 1996. Rain-induced cracking of sweet cherries: Its causes and prevention, p. 297-327. In: A.D. Webster and N.E. Looney (eds.). Cherries: Crop physiology, production and uses. CAB Intl., Wallingford, UK.

Considine, J. and K. Brown. 1981. Physical aspects of fruit growth: Theoretical analysis of distribution of surface growth forces in fruit in relation to cracking and splitting. Plant Physiol. 68:371-376.

De Belie, N., I.C. Hallett, F.R. Harker, and J. De Baerdemaeker. 2000. Influence of ripening and turgor on the tensile properties of pears: A microscopic study of cellular and tissue changes. J. Amer. Soc. Hort. Sci. 125:350-356.

Geyer, U. and J. Schönherr. 1988. In vitro test for effects of surfactants and formulations on permeability of plant cuticles, p. 21-33. In: B. Cross and H.B. Scher (eds.). Pesticide formulations: Innovations and developments. Amer. Chem. Soc., Washington, DC.

Glenn, G.M. and B.M. Poovaiah. 1989. Cuticular properties and postharvest calcium applications influence cracking of sweet cherries. J. Amer. Soc. Hort. Sci. 114:781-788.

Grimm, E., S. Peschel, T. Becker, and M. Knoche. 2012. Stress and strain in the sweet cherry skin. J. Amer. Soc. Hort. Sci. 137:383-390.

Hansen, M. 2011. When is the best time to pick? 15 Mar. 2011. <http:// www.goodfruit.com/when-is-the-best-time-to-pick/>.

Hovland, K.L. and L. Sekse. 2004. Water uptake through sweet cherry (Prunus avium L.) fruit pedicels: Influence of fruit surface water status and intact fruit skin. Acta Agr. Scandinavica Section B Soil Plant Sci. J. 54:91-96.

Kar, F. and N. Arslan. 1999. Effect of temperature and concentration on viscosity of orange peel pectin solutions and intrinsic viscositymolecular weight relationship. Carbohydr. Polym. 40:277-284.

Kertesz, Z.I. and B.R. Nebel. 1935. Observations on the cracking of cherries. Plant Physiol. 10:763-772.

Knoche, M., M. Beyer, S. Peschel, B. Oparlakov, and M.J. Bukovac. 2004. Changes in strain and deposition of cuticle in developing sweet cherry fruit. Physiol. Plant. 120:667-677.

Knoche, M. and S. Peschel. 2006. Water on the surface aggravates microscopic cracking of the sweet cherry fruit cuticle. J. Amer. Soc. Hort. Sci. 131:192-200.

Knoche, M., E. Grimm, and H.J. Schlegel. 2014. Mature sweet cherries have low turgor. J. Amer. Soc. Hort. Sci. 139:3-12.

Kondo, S. and C. Danjo. 2001. Cell wall polysaccharide metabolism during fruit development in sweet cherry 'Satohnishiki' as affected by gibberellic acid. J. Jpn. Soc. Hort. Sci. 70:178-184.

Lang, A. and H. Düring. 1990. Grape berry splitting and some mechanical properties of the skin. Vitis 29:61-70.

Lang, A. and H. Düring. 1991. Partitioning control by water potential gradient: Evidence for compartmentation breakdown in grape berries. J. Expt. Bot. 42:1117-1122. 
Matas, A.J., E.D. Cobb, J.A. Bartsch, D.J. Paolillo, and K.J. Niklas. 2004. Biomechanics and anatomy of Lycopersicum esculentum fruit peels and enzyme-treated samples. Amer. J. Bot. 91:352-360.

McGuire, R.G. 1992. Reporting of objective color measurements. HortScience 27:1254-1255.

Measham, P.F., S.A. Bound, A.J. Gracie, and S.J. Wilson. 2009. Incidence and type of cracking in sweet cherry (Prunus avium L.) are affected by genotype and season. Crop Pasture Sci. 60:1002-1008.

Measham, P.F., S.A. Bound, A.J. Gracie, and S.J. Wilson. 2010. Vascular flow of water induces side cracking in sweet cherry (Prunus avium L.). Adv. Hort. Sci. 24:243-248.

Niklas, K.J. 1992. Plant biomechanics: An engineering approach to plant form and function. Univ. Chicago Press, Chicago, IL.

Oey, M.L., E. Vanstreels, J. De Baerdemaeker, E. Tijskens, H. Ramon, M.L.A.T.M. Hertog, and B. Nicolai. 2007. Effect of turgor on micromechanical and structural properties of apple tissue: A quantitative analysis. Postharvest Biol. Technol. 44:240-247.

Peschel, S. and M. Knoche. 2005. Characterization of microcracks in the cuticle of developing sweet cherry fruit. J. Amer. Soc. Hort. Sci. 130:487-495.

Schumann, C., H.J. Schlegel, E. Grimm, M. Knoche, and A. Lang. 2014. Water potential and its components in developing sweet cherry. J. Amer. Soc. Hort. Sci. 139:349-355.

Sekse, L., K.L. Bjerke, and E. Vangdal. 2005. Fruit cracking in sweet cherries: An integrated approach. Acta Hort. 667:471-474.
Simon, E.W. 1977. Leakage from fruit cells in water. J. Expt. Bot. 28:1147-1152.

Tilbrook, J. and S.D. Tyerman. 2008. Cell death in grape berries: Varietal differences linked to xylem pressure and berry weight loss. Funct. Plant Biol. 35:173-184.

Verner, L. and E.C. Blodgett. 1931. Physiological studies of the cracking of sweet cherries. Univ. Idaho Agr. Expt. Sta. Bul. 184.

Vincent, J.F.V. 1990a. Structural biomaterials, revised ed. Princeton Univ. Press, Princeton, NJ.

Vincent, J.F.V. 1990b. Fracture properties of plants. Adv. Bot. Res. 17:235-287.

Weichert, H. and M. Knoche. 2006. Studies on water transport through the sweet cherry fruit surface. 10. Evidence for polar pathways across the exocarp. J. Agr. Food Chem. 54:3951-3958.

Weichert, H., C.V. Jagemann, S. Peschel, M. Knoche, D. Neumann, and W. Erfurth. 2004. Studies on water transport through the sweet cherry fruit surface: VIII. Effect of selected cations on water uptake and fruit cracking. J. Amer. Soc. Hort. Sci. 129:781-788.

Winkler, A., M. Ossenbrink, and M. Knoche. 2015. Malic acid promotes cracking of sweet cherry fruit. J. Amer. Soc. Hort. Sci. 140:280-287.

Yamaguchi, M., I. Sato, and M. Ishiguro. 2002. Influences of epidermal cell sizes and flesh firmness on cracking susceptibility in sweet cherry (Prunus avium L.) cultivars and selections. J. Jpn. Soc. Hort. Sci. 71:738-746. 